\title{
An Assessment of the Quality of Services of Kenya Power (KP) Ltd in Restoring Supply After Unplanned Interruptions Using Statistical Quality Control
}

\author{
George Yogo Odongo ${ }^{1, *}$, Christopher Ngacho ${ }^{2}$ \\ ${ }^{1}$ Department of Computer Science, Faculty of Science, Egerton University, Njoro, Kenya \\ ${ }^{2}$ Department of Management Science, Faculty of Commerce, Kisii University, Kisii, Kenya
}

Email address:

godongo@egerton.ac.ke (G. Y. Odongo), cngacho@yahoo.com (C. Ngacho)

\section{To cite this article:}

George Yogo Odongo, Christopher Ngacho. An Assessment of the Quality of Services of Kenya Power (KP) Ltd in Restoring Supply After Unplanned Interruptions Using Statistical Quality Control. International Journal of Economics, Finance and Management Sciences.

Vol. 3, No. 3, 2015, pp. 194-203. doi: 10.11648/j.ijefm.20150303.16

\begin{abstract}
The purpose of this study was to apply statistical quality control (SQC) techniques and tools to assess the customer's experience of quality as offered by Kenya Power Ltd. It also seeks to determine whether or not the services of the company were in statistical control. The study was designed as a descriptive survey. The population consisted of 65,830 customers within Nakuru town and its environs from which four hundred customers were sampled. The sample population was stratified so that 286 were domestic consumers while the remaining 114 were non-domestic consumers. Stratified random sampling was used. The collected data was coded and summarized in the form of tables and entered into the SPSS program. Customers' experiences were obtained and used to draw control charts, which were analyzed. It was found that the customers' experience of service as regards the restoration of supply after unplanned interruptions was not in statistical control for both domestic and non-domestic consumers. These results are an indictment of the qualities of service of Kenya Power. The implication for the managers of service processes at Kenya Power is that they must ensure optimal service quality in the firm. In particular, urgent steps must be taken to identify the root cause or causes of special variation that result in service invariability and instability. We strongly advocate for the intensified use of statistical quality control tools in the utility services sector and particularly at Kenya Power, as a means of monitoring the production and service quality, and enabling the firm to take timely and appropriate action to correct undesirable deviation in production quality.
\end{abstract}

Keywords: Statistical Quality Control, Control Charts, Quality of Service, Utility Services

\section{Introduction}

\subsection{Background of the Study}

The concept of quality is one that has existed for several decades now though its conceptualization has differed in different periods. In the early twentieth century, quality management meant inspecting products to ensure that design specifications were met. In the intervening periods between the 1940 s and $50 \mathrm{~s}$, quality became more statistical in nature. Statistical sampling techniques were employed to assess quality, and quality control charts were drawn to monitor production processes (Hossain, 2008; Mukherjee, 2012). In the $1960 \mathrm{~s}$, the concept took on a broader meaning, thanks to the work of the infamous quality gurus in the likes of Feignebaum, Crosby, Ishikawa and Taguchi. At that time, quality began to be viewed as something that encompassed the entire organization and not only the production process. Since all functions were responsible for the quality of a product, all of them shared the costs of poor quality. In the 1970's and 80's, manufacturers in the auto and consumer goods industry of the US lost substantial market share due to foreign competition. These foreign competitors produced lower-priced goods with unmatched superior quality. To survive, companies made far-reaching changes to their quality programs. Consultants were hired and companies instituted intense quality training programs for their employees. Unwittingly, a new concept of quality emerged. Quality consequently took on a strategic meaning. In today's' contemporary world, successful companies understand that quality provides a competitive advantage and that by defining quality as meeting or exceeding customer expectations, they place the customer first 
(Mauch, 2010).

\subsection{Research Objective}

The main objective of this work was to carry out an assessment of the quality of services provided by Kenya Power to its customers and find out whether or not; the services are in a state of statistical control. Specifically, the study seeks to assess whether the customers' experience of service as regards the restoration of supply after unplanned interruptions is in statistical control.

\subsection{Conceptual Framework}

The design of the conceptual framework outlines the independent and dependent variables in the study. The independent variable (organizational factors) is conceptualized into operational factors and human characteristics and related with implementation of project management information system. Three intervening and four moderating variables are also captured in the framework to ensure reliability of making generalizations after data analysis.

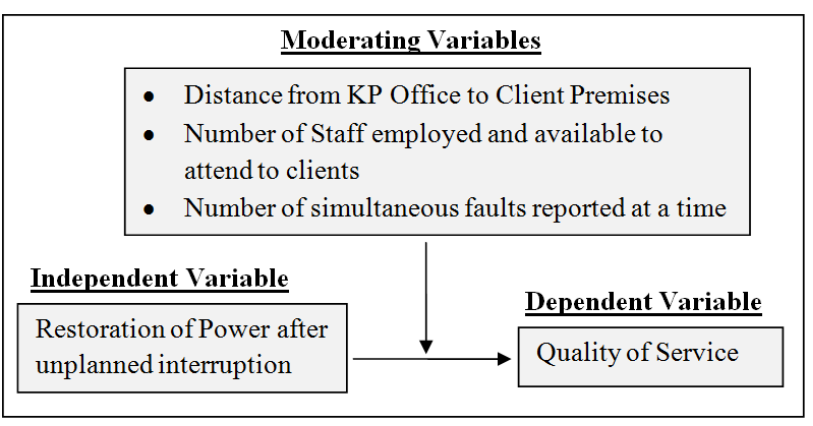

Figure 1. The Conceptual Framework).

\section{Literature Review}

\subsection{Historical Background of Quality}

For over fifty (50) years now, the principal application domain for statistical quality control has been process control and improvement in the manufacturing industry (Scordaki \& Psarakis, 2005; Nakhai, 2009). The most common process control technique has been control charting. However, the number of applications reported in domains outside of conventional production systems has seen a steady rise over the years. Scordaki \& Psarakis (2005) identified four such application domains. The first of these is in engineering, industrial and environmental applications. The second application area is in healthcare, the third, general service sector application and the fourth, statistical applications. Scordaki \& Psarakis (2005) further identified four principal objectives for these application domains. The first objective is to monitor processes where the objective is to watch over and control a process in order to maintain process stability and in many cases to enable process improvement. The second objective is to plan. SQC charts are used to derive effective plans or schedules, particularly for maintenance scheduling.
The third objective is in assessing customer satisfaction. SQC charts have been used to assess customer satisfaction in a range of application domains to detect high levels of satisfaction and dissatisfaction. The fourth and final objective is in forecasting. SQC charts are used to generate or optimize a forecasting model.

\subsection{Distinctive Characteristics of Service Firms}

A question that often arises in the study of service-oriented organizations is, how different is the management of such operations when contrasted with manufacturing firms? In answering this question, Bitran \& Lojo, (1993) said that though the basic management principles are the same for both services and manufacturing firms, there are however some distinctive characteristics between service and manufacturing firms. The following attributes of services suggest the need for different skills in the management process; intangibility, perishability, heterogeneity, and simultaneity. Subsequent sub-sections discuss each of these attributes in turn.

\subsubsection{Intangibility}

As opposed to a product producing firm, service firms usually sell bundles of goods and services, comprising both physical items and intangibles that are both explicit - having sensual benefits, and implicit - having psychological benefits (Roberts, 2005; Ograjenšek, 2002; Bitran and Lojo, 1993). The intangible nature of service products makes it difficult to promote their consumption exclusively on technical grounds. They satisfy customer needs associated with convenience and personal satisfaction, and frequently involve feelings such as anxiety, relief, or joy. These factors are of course, also present in the consumption of tangible goods. However, the physical characteristics of manufactured goods provide some objective measures on which customers can assess their purchases.

\subsubsection{Perishability}

The fact that most tangible goods have extended life means that they can be stocked and distributed through a network of outlets. Such goods can be produced long in advance of their consumption and stocked at strategic distribution centers (Ograjenšek, 2002; Juneja, Ahmad, and Kumar, 2011; Bitran and Lojo, 1993). In contrast, the intangible nature of services means that they are perishable and cannot be inventoried in the traditional sense. Consequently, managers in service organization are often faced with situations in which their facilities and other assets are idle for long periods, which is very costly.

\subsubsection{Heterogeneity}

Although technological advancements have created vast opportunities for services to be delivered by machines, not all services can be so delivered. It is still common to encounter services delivered by human being (Heizer, J., and Render, B., 2011; Juneja, Ahmad, and Kumar, 2011; Bitran and Lojo, 1993). Humans, however tend to be inconsistent in their behavior and therefore in the delivery. However, even where there is consistency in delivery, the consumers' experience may be affected by other factors other than those directly 
attributable to the service provider, such their state of happiness, attitudes etc. This fact therefore creates a major challenge for the managers of quality in service firms.

\subsubsection{Simultaneity}

A salient feature that is present in all services is that they are produced and consumed at the same time. This characteristic presents a challenge for the manager of quality since the service cannot be inspected before consumption (Ograjenšek, 2002; Heizer, J., and Render, B., 2011; Bitran and Lojo, 1993). If a mistake occurs during delivery, it will be witnessed by the customer and subsequently be very difficult or expensive to correct.

\subsection{Measures of Quality in Service Firms}

Conformance to quality can be measured based on either or both, internal or external parameters. For internal parameters, the measures of quality have much in common with the well-known measures widely used in the control of manufacturing processes. Measures of external conformance are more complex due to the abstract nature of some of the qualities and due to the subjective reactions of consumers. An obvious source of data on external conformance is the cross-section of consumer complaints and claims, although many annoyed consumers will not take the trouble to complain. However, the complaints received do represent a sample of the types of annoyance to which all consumers are subject. A second method of measure of external performance is through solicitation of consumer comments. A typical form of this is the appraisal card made available to consumers in hotel rooms and restaurants. Some companies use the summaries of these cards as the basis for regular management reports. Additionally, some companies design special surveys of customer reaction, through letter questionnaires, telephone contacts and personal interview. The techniques used follow conventional market research practice. Measures of service quality have to date been on an industry-by-industry basis, and this is expected to continue in the near future. Some service companies supplement their regular measures of quality by use of periodic audits. These audits are all pervasive, covering both internal and external aspects of quality.

\subsection{Causes of Variation of Quality}

Any production process, regardless of how well designed or carefully maintained, will expectedly produce goods of varying quality (Montgomery, 2009; Olatunde, 2009). This variability occurs naturally is healthy and is not indicative of the presence of any underlying problem(s). Such variability, being random, is inherent to a process (Mahesh, and Prabhuswamy, 2010). In the framework of statistical quality control, this natural variability is often called a "stable system of chance causes" (Montgomery, 2009). A process that is operating with only chance causes of variation present is said to be in statistical control. It is highly desirable that a process be and remain in statistical control.

The other kind of variability that may occasionally present in the output of a process is due to assignable causes. In general terms, variability due to assignable causes arises from three sources; improperly adjusted or controlled machines, operator errors, or defective raw materials. Such variability is generally large as compared to natural variability and usually represents an unacceptable level of process performance. Sources of variation that are not part of the chance causes are referred to as assignable causes. A process that is operating in the presence of assignable or special causes is said to be an out-of-control process. It is highly undesirable that a process operate statistically out-of-control. Special causes of variation should be eliminated as far as practically possible (Doty, 1996).

Fig. 2 illustrates these chance and assignable causes of variation. From the Fig. 2 , it is seen that until time $t_{1}$, the process shown in this figure is in control. That is, only chance causes of variation are present. As a result, both the mean and standard deviation of the process are at their in-control values of $\mu_{0}$ and $\sigma_{0}$ respectively. At time $t_{1}$, an assignable cause occurs. The effect of this is to shift the process mean to a new value $\mu_{1}>\mu_{0}$. At time $t_{2}$, another assignable cause occurs, resulting in $\mu=\mu_{0}$, but now the process standard deviation has shifted to a larger value $\sigma_{1}>\sigma_{0}$. At time $t_{3}$, there is another assignable cause presents resulting in both the process mean and standard deviation taking on out-of-control values. From time $t_{1}$ forward, the presence of assignable causes has resulted in an out-of-control process.

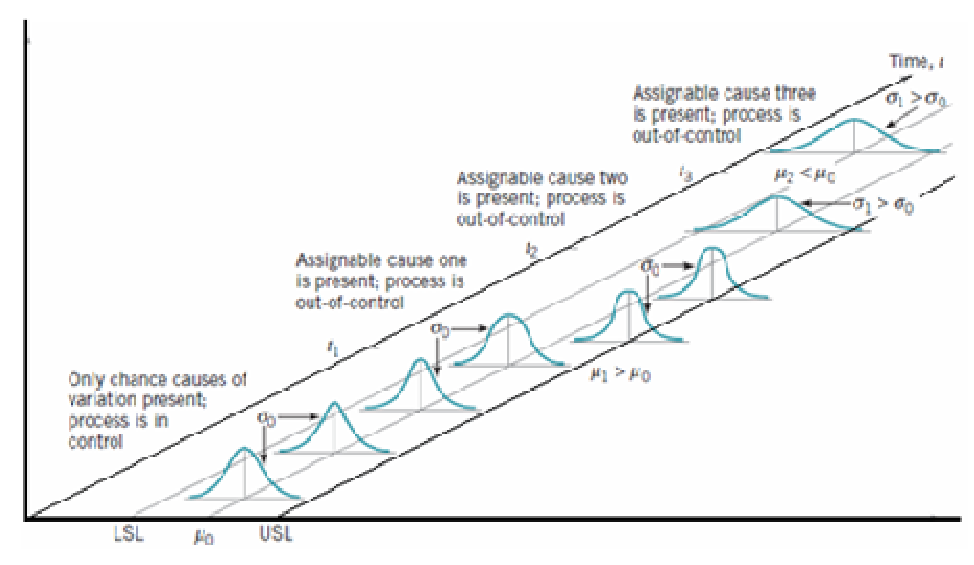

Figure 2. Process Quality Characteristics Source: Montgomery, 2009. 
Processes will often operate in the in-control state for relatively long periods of time. But since no process remains stable forever, assignable causes eventually occur, seemingly at random, resulting in a shift to an out-of-control state where a larger proportion of the process output does not conform to requirements. It can be noted from Fig. 2, that when the process is in control, most of the production will fall between the lower and upper specification limits. However when the process is out of control, a higher proportion of the process lies outside of these specifications.

\subsection{Assumptions Underlying Statistical Quality Control}

Statistical quality control is usually seen as being more than just a set of statistical procedures; it also encompasses a set of assumptions about the underlying philosophy of quality management. The first assumption on which the rationale of SPC depends is that important quality characteristics can be and should be measured (Wood, 1994). The risks of failing to measure are obvious in that problems may not be noticed, changes may be brought in without a clear analysis of the situation, and there will be no clear evidence of any improvements. The second assumption is that the aim should be the prevention of problems before they occur, rather than just diagnosing them after they have occurred. The goal should be to improve the future rather than simply measuring the past. There are two reasons for identifying and measuring problems after they have occurred: first to correct the problem (perhaps by scrapping or reworking the component), and second to learn from past performance in order to improve future performance. The aims of SPC fall entirely in the second category. The goal is to improve the process so that eventually - identifying and correcting errors becomes unnecessary because none exist. This improves quality and reduces waste because the process has improved, and also produces large savings in the amounts which need to be spent on inspection. This argument is as valid in the education industry (for example) as it is in the motor industry: it is not sufficient to identify student errors in order to fail students or correct misunderstandings (i.e. scrap or rework); it is also important to learn from the errors in order to improve the future teaching process and so prevent future errors. Thirdly, wherever possible the analysis should concentrate on the process rather than the output (Wood, 1994). This is likely to be the most effective way of achieving the previous aim. Concentrating on the output is an inefficient strategy because it fails to provide information about which aspects of the production process could usefully be improved, and because of the delay, it may entail. By concentrating on the output rather than the process, a manufacturer of cars for example may, end up with a batch of finished cars all of which have to be scrapped or reworked because of defects in the bodywork. It clearly makes far more sense to monitor each part of the process of manufacture - as it happens - so that problems can be found and remedial action taken immediately to ensure that the problem does not recur. Exactly the same arguments apply to service processes such as education and catering. Lastly, the resources devoted to testing, monitoring and inspection should be as few as possible. This usually means that the amount of data used should be the minimum to achieve the purpose. A common practice for mean and a range control chart, for example, is to use samples of five items only (Wood, 1994). Indeed, a strong case could be made for the claim that it is these principles, and not the techniques themselves, that are the real essence of SQ

\subsection{Statistical Quality Control Techniques}

Statistical quality control methods extend the use of descriptive statistics to monitor the quality of the product and process. Using statistical quality control, we can determine the amount of variation that is common or normal. Then we monitor the production process to make sure production stays within this normal range. That is, we want to make sure the process is in a state of control. The most commonly used tool for monitoring the production process is a control chart. Different types of control charts are used to monitor different aspects of the production process.

\subsubsection{Pareto Diagram}

The primary purpose and use of Pareto diagrams is to focus improvement efforts on the most important causes by identifying the vital few and trivial many causes. In studying the problems, it can be generally observed that $80 \%$ of the problems result from only $20 \%$ of the potential causes. The Pareto Chart indicates identifies problems, priorities them and gives in percentages of the total what each presents. Pareto diagrams are mainly applied in sales, production, maintenance, safety and finance.

\subsubsection{Control Charts}

A control chart (also called process chart or quality control chart) is a graph that shows whether a sample of data falls within the common or normal range of variation. A control chart has upper and lower control limits that separate common causes from assignable causes of variation. The common range of variation is defined by the use of control chart limits. A process is said to be out of control when a plot of data reveals that one or more samples fall outside the control limits (Montgomery, 2009, Oakland, 2008).

The upper and lower control limits on a control chart are usually set at \pm 3 standard deviations from the mean. If we assume that the data exhibit a normal distribution, these control limits will capture 99.73 percent of the normal variation. Control limits can be set at \pm 2 standard deviations from the mean. In that case, control limits would capture 95.44 percent of the values. Fig. 3 shows the percentage of values that fall within a particular range of standard deviation.

Looking at Fig. 3, it can be concluded that observations that fall outside the set range represent assignable causes of variation. However, there is a small probability that a value that falls outside the limits is still due to normal variation. This is called Type I error, with the error being the chance of concluding that there are assignable causes of variation when 
only normal variation exists (Oakland, 2008, Chandra, 2001). Another name for this is alpha risk $(\alpha)$, where alpha refers to the sum of the probabilities in both tails of the distribution that falls outside the confidence limits. The chance of this happening is given by the percentage or probability represented by the enclosed areas of Fig. 3. For limits of \pm 3 standard deviations from the mean, the probability of a Type I error is $0.26 \%(100 \%-99.74 \%)$, whereas for limits of \pm 2 standard deviations it is $4.56 \%(100 \%-95.44 \%)$.

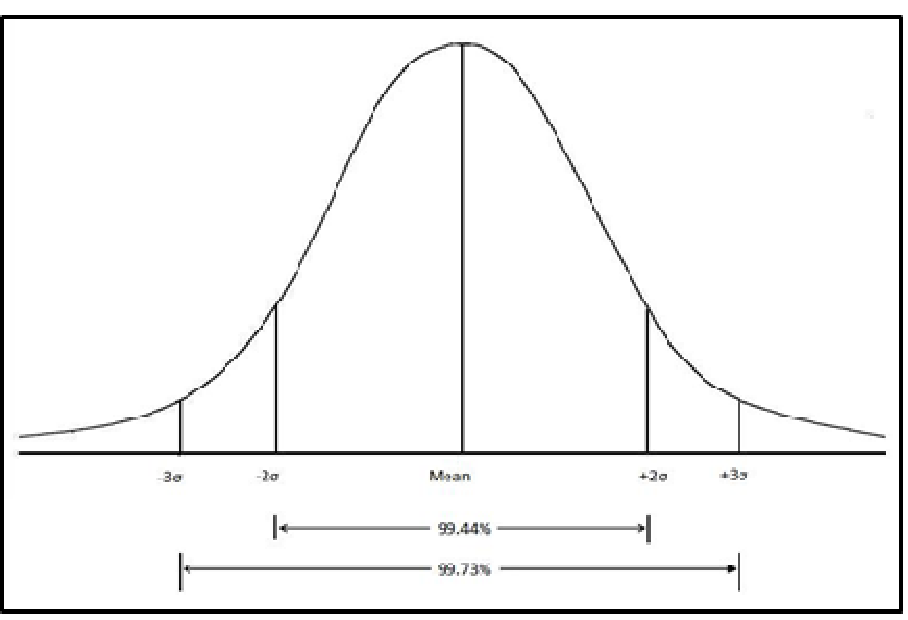

Figure 3. Percentage of values captured by different ranges of standard deviation (Adapted: Chandra, 2001).

\subsection{Types of Control Charts}

Control charts are one of the most commonly used tools in statistical quality control. They can be used to measure any characteristic of a product, such as the weight of a packet of flour, the number of biscuits in a box, or the volume of bottled soda. The different characteristics that can be measured by control charts can be divided into two groups: variables and attributes (Oakland, 2008, Montgomery, 2009). A control chart for variables is used to monitor characteristics that can be measured and that have a continuous range of values, such as weight, volume or height. A bottle of Coca-Cola soda soft drink bottling operation is an example of a variable measure since the amount of liquid in the bottles is measured and can take on a number of different values that are non-discrete. On the other hand, a control chart for attributes is used to monitor characteristics that have discrete values and that can be counted. Often they can only be evaluated with a simple yes or no type decision. Examples include color, taste, or smell. The monitoring of attributes usually takes less time than that of variables because a variable needs to be measured. An attribute requires only a single decision, such as yes or no, good or bad, pass or fail, acceptable or unacceptable, etc. or counting the number of defects for example the number of broken biscuits in the box. Statistical quality control is used to monitor many different types of variables and attributes. In the next section, we carry out a review of empirical literature particularly of studies conducted at Kenya Power (formerly K.P.L.C.).

\section{Research Methodology}

\subsection{Research Design}

The study used survey design. Survey design was found important because it describes an existing observed phenomenon and establishes causal relationships (Kathuri \& Pals, 1993). Apart from being an excellent way of gathering large quantitative data, surveys are also an efficient way of getting an insight into people's thoughts, opinions and experiences (Radhakrishna, 2007).

\subsection{Target Population and Study Area}

The target population consisted of electricity consumers within Nakuru Town and its environs who hold domestic and non-domestic accounts for the duration of the study. As of August 2013, the total number of such accounts was 65,830 (Source: Kenya Power Database) distributed as follows.

Table 1. Distribution of consumer accounts by type in Nakuru Town Area.

\begin{tabular}{ll}
\hline Types of Account & Total Number \\
\hline Domestic Consumers & 47,149 \\
Non-domestic Consumers & 18,681 \\
Total & 65,830 \\
\hline
\end{tabular}

\subsection{Sampling Design}

Stratified sampling was used. For the purpose of the study, domestic and non-domestic consumers living in and around Nakuru County were used in the study. Stratified sampling was used to obtain samples from each of the two categories of users as shown in Table 2. The following formula made known by Krejcie \& Morgan (1970) was used to calculate the sample size.

$$
\text { Sample Size }=\frac{(\text { Z.Score })^{2} \times \operatorname{StdDev} \times(1-\text { StdDev })}{(\text { margin of error })^{2}}
$$

The Z-Score and the confidence interval were selected as 1.96 and $\pm 5 \%$ respectively. A Z-Score of 1.96 corresponds to a confidence level of $95 \%$. The standard deviation is difficult 
to determine before the study is conducted but a safe choice of 0.5 is made for the sake of moving the study forward (Kothari, 2004). With this, the sample size was obtained to be 384.16 , but was rounded up to the nearest hundreds, i.e. 400. The distribution of this sample across each stratum as follows.

Table 2. Stratification of Sample Population.

\begin{tabular}{llll}
\hline Types of Account & Total & Percentage & Sample \\
\hline Domestic & 47,149 & 71.6 & 286 \\
Non-domestic & 18,681 & 28.4 & 114 \\
Total & 65,830 & 100 & 400 \\
\hline
\end{tabular}

Accordingly, the sample sizes for the domestic and non-domestic consumers were 286 and 114 respectively.

\subsection{Data Collection}

This study utilized both primary and secondary data. Primary data was captured by way of questionnaires consisting of closed-ended questions. It was tested for reliability and validity using the translation validity method. With this, a test was done for both face and content validity. The questionnaire was then piloted on about $10 \%$ (40) of the target respondents. Of these, 29 were domestic consumers and the rest (11) non-domestic. The feedback was used to correct the questionnaire which was subsequently administered to the envisaged sample. The questionnaires were hand delivered to each respondent who were then given time to fill them up.

Secondary data was collected from existing data to support the primary data. Specifically, the procedure of developing control charts, tables of constants and formulas used were obtained in this manner.

\subsection{Data Analysis}

The collected data was coded and summarized in the form of tables and entered into a Microsoft Excel worksheet and similarly into the SPSS program. The demographic profile of the respondents was analyzed using frequency tables and graphs. Samples of five respondents in each category were randomly clustered. The mean value and range for each cluster was calculated and used to draw control charts. The charts were drawn using SPSS version 20. Specifically range (R) and mean $(\overline{\mathrm{X}})$ charts were drawn. Control charts were selected because they have the ability to tell apart variation due to assignable causes from random causes of variation. In addition to identifying of out-of-control processes, control charts can be used to identify trends and reduce overall system variability.

\section{Results and Discussion}

We present findings on the assessment of quality of services of Kenya Power using statistical quality control. The study was carried out in Nakuru town and its environs. A stratified sample of four hundred was selected. Of these, 286 were domestic consumers and 114 were non-domestic consumers. Questionnaires were randomly issued and responses obtained.

Both the range and mean Charts ( $\overline{\mathrm{X}}$-bar chart) were used for this quality attribute. The mean chart ( $\overline{\mathrm{X}}$-bar chart) showed the variation the process by plotting the actual mean values of each set of sampled data. The data was plotted against the background of the mean of means of all the samples taken and the upper and lower control limits for the data. These limiting bounds are each three-sigma limits, meaning that almost all $(99.73 \%)$ of the variation in the process are expected to fall within a six-sigma limit. Sigma, represented by the Greek symbol $\sigma$, is the standard deviation of a distribution. The range chart (R-chart) is similar to the mean chart in having upper and lower (three-sigma) control limits, but the data plotted for each sample is now the range between the largest and the smallest value in the sample. By plotting the range of values, variation within each sample is more apparent. Signals from the mean chart or range chart to detect processes that are out of control was done by identifying outliers, shifts, trends, or cycles (Oakland, 2008, Montgomery, 2009).

An outlier is any data point that is above the UCL or below the LCL i.e. any point that is beyond $\pm 3 \sigma$. Because the control limits are calculated from probability theory, an outlier is highly unlikely in a process with only common cause variation.

A shift is when a process generates nine points in a row on the same side of the centerline. While this may be possible, it is highly unlikely. A shift indicates a shift in the mean. This is a strong indicator that the process has changed and warrants investigation.

A trend is defined as six consecutive points, each higher than the previous point or six consecutive points, each lower than the previous point. It indicates a special cause with a gradual effect.

Fourteen consecutive points that alternate up and down signal repeating patterns, also called cycles (Oakland, 2008, Montgomery, 2009). This pattern signals cyclical change in the process that is repetitive and certainly warranting investigation.

\subsection{Demographic Information on the Respondents}

The first item on demographics information sought was on the gender distribution of the respondents. This demographic analysis is only relevant for consumers who hold domestic accounts since non-domestic consumers are non-human entities. The respondents' responses are presented in Table 3 below.

The study found out that most of the domestic customers of Kenya Power in Nakuru and its environs were men at 59.4\% while women were about $40.5 \%$.

Table 3. Distribution of respondents by gender.

\begin{tabular}{lll}
\hline Gender & Frequency & Percent \\
\hline Male & 170 & 59.4 \\
Female & 116 & 40.5 \\
Total & 286 & 100.0 \\
\hline
\end{tabular}




\subsection{Time Taken to Restore Supply after an Unplanned Power Interruption}

The respondents were also asked to indicate how much time Kenya Power typically takes to restore supply after an unplanned power interruption. An analysis was done for each category of consumers that is domestic and non-domestic. The results are presented in the sub-sections below.

\subsubsection{Restoration of Supply after Unplanned Interruptions: Domestic Users}

In order to study the sample variability in non-domestic consumers, the data was randomly clustered into sets of eight as shown in Table 4 below.

Table 4. Grouping of the responses in domestic consumers.

\begin{tabular}{|c|c|c|c|c|c|c|c|c|c|c|}
\hline & $\mathbf{O b}$ & & & & & & & & $\overline{\mathbf{X}}$ & $\mathbf{R}$ \\
\hline Cluster 1 & 5 & 9 & 3 & 9 & 9 & 9 & 11 & 5 & 7.5 & 8 \\
\hline Cluster 2 & 3 & 5 & 3 & 5 & 5 & 7 & 3 & 11 & 5.3 & 8 \\
\hline Cluster 3 & 3 & 9 & 5 & 5 & 11 & 9 & 9 & 9 & 7.5 & 8 \\
\hline Cluster 4 & 11 & 3 & 11 & 11 & 11 & 5 & 11 & 5 & 8.5 & 8 \\
\hline Cluster 5 & 3 & 9 & 11 & 11 & 5 & 11 & 11 & 7 & 8.5 & 8 \\
\hline Cluster 6 & 9 & 11 & 7 & 7 & 7 & 11 & 11 & 9 & 9 & 4 \\
\hline Cluster 7 & 9 & 11 & 5 & 3 & 5 & 9 & 7 & 3 & 6.5 & 8 \\
\hline Cluster 8 & 11 & 5 & 11 & 9 & 11 & 5 & 9 & 11 & 9 & 6 \\
\hline Cluster 9 & 3 & 11 & 1 & 7 & 11 & 5 & 11 & 11 & 7.5 & 10 \\
\hline Cluster 10 & 11 & 5 & 9 & 11 & 5 & 5 & 5 & 7 & 7.3 & 6 \\
\hline Cluster 11 & 3 & 3 & 7 & 9 & 5 & 11 & 9 & 11 & 7.3 & 8 \\
\hline Cluster 12 & 9 & 3 & 3 & 11 & 11 & 5 & 9 & 5 & 7 & 8 \\
\hline Cluster 13 & 11 & 7 & 11 & 7 & 3 & 11 & 11 & 5 & 8.3 & 8 \\
\hline Cluster 14 & 1 & 3 & 11 & 9 & 3 & 3 & 7 & 3 & 5 & 10 \\
\hline Cluster 15 & 11 & 11 & 11 & 9 & 5 & 7 & 11 & 11 & 9.5 & 6 \\
\hline Cluster 16 & 9 & 1 & 3 & 3 & 9 & 11 & 3 & 11 & 6.3 & 10 \\
\hline Cluster 17 & 3 & 9 & 50 & 30 & 11 & 5 & 11 & 11 & 16.3 & 47 \\
\hline Cluster 18 & 11 & 7 & 50 & 50 & 3 & 5 & 5 & 30 & 20.1 & 47 \\
\hline Cluster 19 & 3 & 7 & 5 & 3 & 7 & 9 & 5 & 7 & 5.8 & 6 \\
\hline Cluster 20 & 7 & 5 & 11 & 1 & 50 & 11 & 5 & 11 & 12.6 & 49 \\
\hline Cluster 21 & 7 & 5 & 3 & 7 & 5 & 7 & 50 & 1 & 10.6 & 49 \\
\hline Cluster 22 & 7 & 5 & 30 & 7 & 11 & 1 & 11 & 30 & 12.8 & 29 \\
\hline Cluster 23 & 5 & 30 & 30 & 1 & 3 & 30 & 9 & 5 & 14.1 & 29 \\
\hline Cluster 24 & 30 & 9 & 11 & 11 & 50 & 50 & 50 & 3 & 26.8 & 47 \\
\hline Cluster 25 & 11 & 5 & 5 & 30 & 1 & 5 & 30 & 11 & 12.3 & 29 \\
\hline Cluster 26 & 9 & 1 & 11 & 3 & 11 & 11 & 11 & 7 & 8 & 10 \\
\hline Cluster 27 & 11 & 11 & 11 & 7 & 3 & 5 & 5 & 3 & 7 & 8 \\
\hline Cluster 28 & 11 & 7 & 7 & 11 & 9 & 7 & 7 & 9 & 8.5 & 4 \\
\hline Cluster 29 & 1 & 3 & 3 & 11 & 11 & 11 & 9 & 11 & 7.5 & 10 \\
\hline Cluster 30 & 11 & 11 & 11 & 7 & 11 & 11 & 3 & 9 & 9.3 & 8 \\
\hline Cluster 31 & 5 & 5 & 7 & 9 & 11 & 11 & 3 & 5 & 7 & 8 \\
\hline Average & & & & & & & & & 9.62 & 16.26 \\
\hline
\end{tabular}

The mean of means was calculated to be 9.62 and the mean range was 16.26. The $\mathrm{R}$ chart shown in Fig. 4 was subsequently drawn.

The R Chart showed that not only are the first 16 sample points on one side of the mean but samples 16, 17, 20, 21 and
24 are outliers. The within-sample variability was not constant. Thus the range chart indicates that the process is not in statistical control. The mean $(\overline{\mathrm{X}})$ chart was then drawn as shown in Fig. 5.

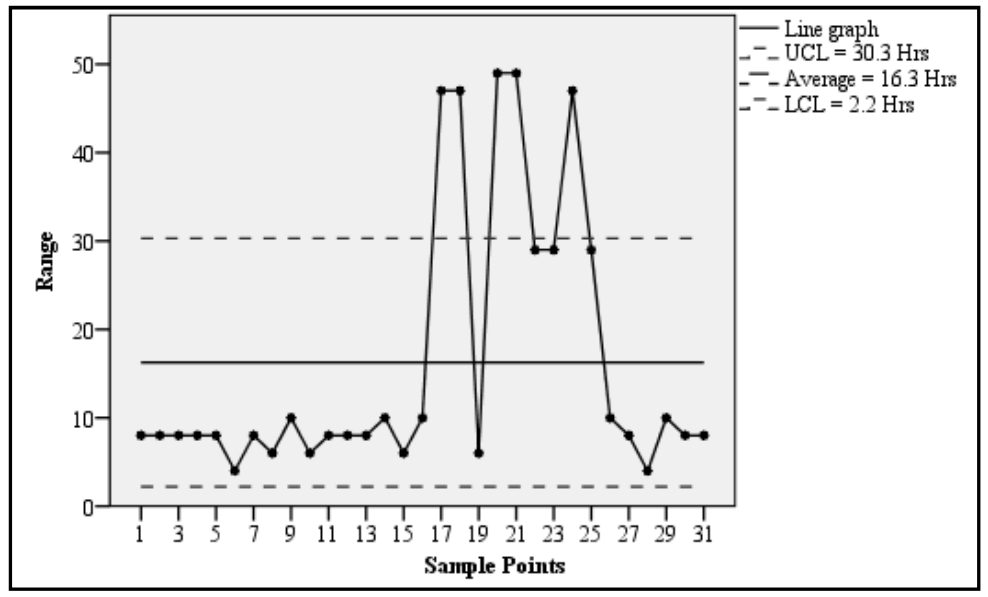

Figure 4. $R$ Chart for domestic consumers. 


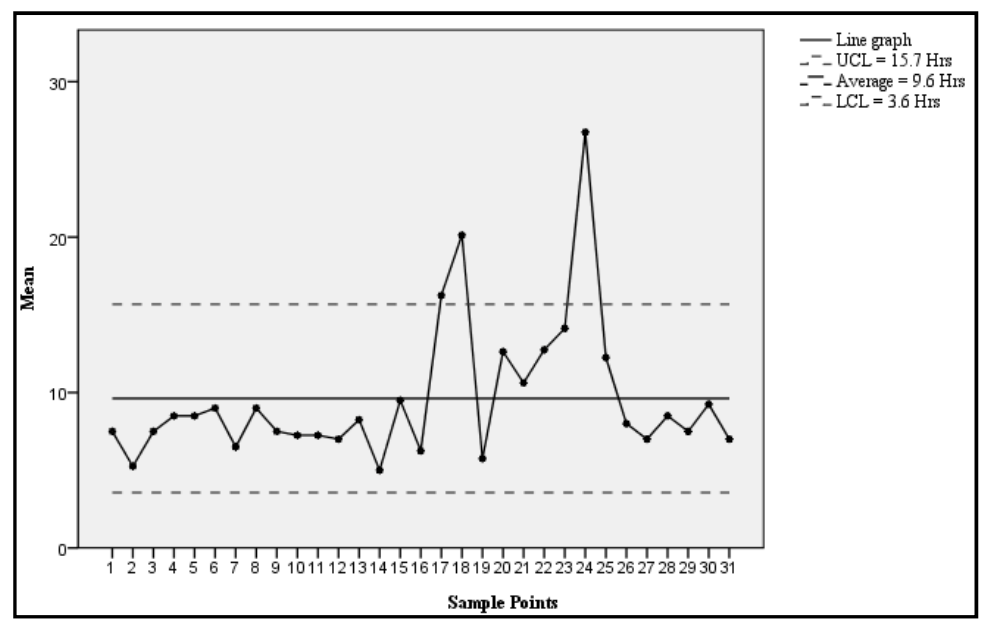

Figure 5. $\bar{X}$ Chart for domestic consumers.

As with the $\mathrm{R}$ chart, it can be seen that the first sixteen consecutive sample points are all below the centre line. This is a clear indication that the process is not in statistical control. In addition, samples 18 and 24 are outliers. With these observations, we therefore concluded that the process is not in statistical control.

\subsubsection{Restoration of Supply after Unplanned Interruptions: Non-Domestic Users}

In order to study the sample variability in non-domestic consumers, the data was randomly clustered into sets of three as shown in Table 5 below.

Table 5. Sub-grouping of the responses in non-domestic consumers.

\begin{tabular}{llllll}
\hline & \multicolumn{3}{l}{ Observations } & \multicolumn{1}{c}{$\mathbf{X}$} & $\mathbf{R}$ \\
\hline Cluster 1 & 9 & 30 & 1 & 13.3 & 29 \\
Cluster 2 & 3 & 5 & 9 & 5.7 & 6 \\
Cluster 3 & 30 & 7 & 1 & 12.7 & 29 \\
Cluster 4 & 7 & 11 & 11 & 9.7 & 4 \\
Cluster 5 & 5 & 11 & 11 & 9.0 & 6 \\
Cluster 6 & 11 & 11 & 5 & 9.0 & 6 \\
Cluster 7 & 11 & 11 & 11 & 11.0 & 0 \\
Cluster 8 & 11 & 5 & 11 & 9.0 & 6 \\
Cluster 9 & 9 & 9 & 5 & 7.7 & 4 \\
Cluster 10 & 11 & 7 & 3 & 7.0 & 8 \\
Cluster 11 & 5 & 7 & 9 & 7.0 & 4 \\
Cluster 12 & 11 & 5 & 3 & 6.3 & 8 \\
Cluster 13 & 5 & 50 & 11 & 22.0 & 45 \\
Cluster 14 & 5 & 11 & 5 & 7.0 & 6 \\
Cluster 15 & 3 & 5 & 11 & 6.3 & 8 \\
Cluster 16 & 11 & 11 & 7 & 9.7 & 4 \\
Cluster 17 & 3 & 11 & 1 & 5.0 & 10 \\
Cluster 18 & 30 & 11 & 30 & 23.7 & 19 \\
Cluster 19 & 30 & 30 & 30 & 30.0 & 0 \\
Cluster 20 & 5 & 3 & 30 & 12.7 & 27 \\
Cluster 21 & 7 & 11 & 11 & 9.7 & 4 \\
Cluster 22 & 11 & 1 & 1 & 4.3 & 10 \\
Cluster 23 & 3 & 9 & 1 & 4.3 & 8 \\
Average & & & & 10.52 & 10.91 \\
\hline & & & & & \\
\hline
\end{tabular}

The mean of means was calculated to be 10.52 and the mean range was 10.91. The $\mathrm{R}$ chart shown in Fig. 6 was subsequently drawn.

The R Chart showed that sample points 1, 2 and 13 are outliers. The within-sample variability was not constant. In addition, samples 4 to 12 created a shift. Thus, the range chart indicates that the process is not in statistical control.

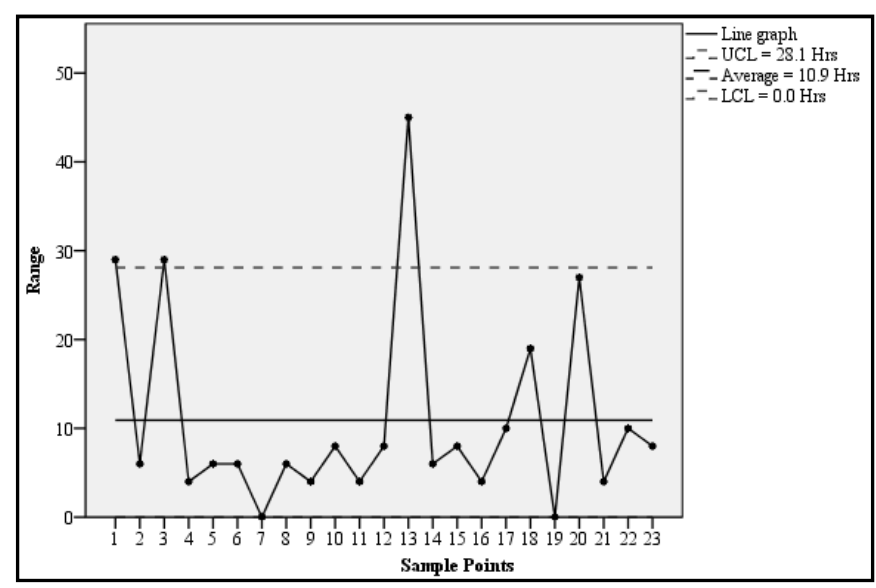

Figure 6. $R$ Chart for non-domestic consumers.

The mean $(\overline{\mathrm{X}})$ chart shown in Fig. 7 was also drawn.

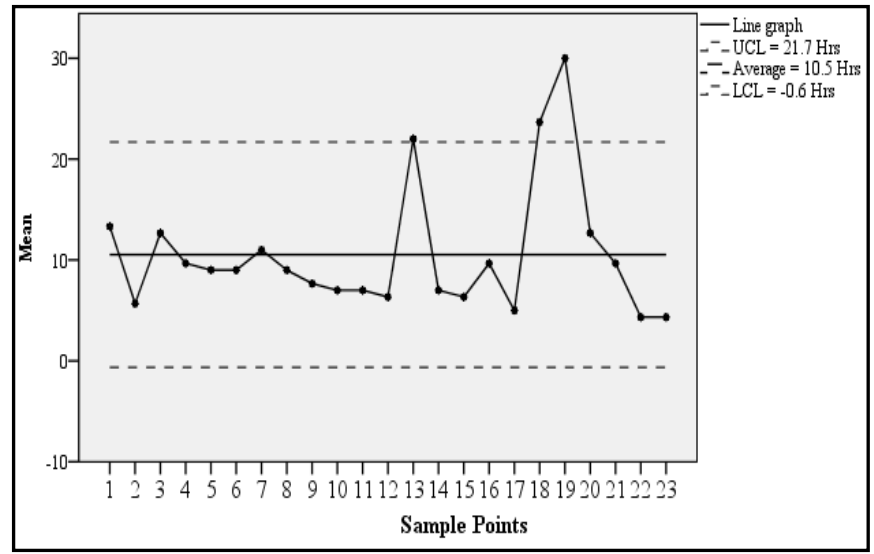

Figure 7. $\bar{X}$ Chart for non-domestic consumers.

From this diagram, it is seen that samples points 13,18 and 
19 are outliers. It is therefore concluded that the process is not in statistical control. Hence, no process capability analysis was carried out.

\section{Conclusions and Recommendations}

\subsection{Conclusions}

The study has established that the quality of services of Kenya Power is erratic, unpredictable and highly unstable. This means that the management of Kenya Power has a lot more to do to ensure optimal service quality in the firm. In particular, urgent steps must be taken to identify the root causes of service instability. Furthermore, the management of Kenya Power must make a commitment to understand and reduce all process variation as much as possible. They must also provide the staff with the tools and training to recognize when variability exists. As Wood (1994) noted, the costs of quality is greatest in the service sector. This means that SQC is even more beneficial in the utility service sector where an opportunity to impress a customer presents itself only once.

\subsection{Recommendations and Possible Areas for Future Work}

Control charts, also known as Shewart charts, have been shown to be very useful in monitoring quality not only in a traditional industrial process but also in non-industrial setting. The two most common techniques are mean charts and range charts. These two parameters when used in conjunction with the central limit theory provide a very effective means of monitoring productivity and ensuring quality. Control charts are important because they prevent unnecessary adjustments to stable processes. They can tell when everything is working well and as such prevents any unnecessary changes such processes. This is consistent with the "if it isn't broken, don't fix it" philosophy. Control charts also provide information about process capability. They provide information about the value of important process parameters and their stability over time. This allows an estimate of process capability to be made. This information is of tremendous benefit to product and process designers. We therefore strongly advocate for the intensified use of statistical quality control tools in the utility services sector and particularly at Kenya Power, as a means of monitoring quality and production, and enabling the firm to take timely and appropriate action to correct undesirable deviation in production quality.

In future, this study can be extended to major urban centers such as Nairobi or Mombasa. An investigation can also be made to determine the extent to which Kenya Power can employ statistical quality control as a measure to detect and curb non-technical electricity losses and additionally to establish the factors that influence such losses in the company.

\section{References}

[1] Bitran G.R., and Lojo, M., (1993). A Framework for Analyzing Service Operations. European management Journal, 11(3), pp. 271-282
[2] Chandra M.J., (2001). Statistical Quality Control. CRC Press LLC

[3] Doty, L.A., (1996). Statistical Process Control. Industrial Press Inc.,U.S.

[4] Feather, J. and Sturges, P. (2003). International Encyclopedia of Information and Library Science. $2^{\text {nd }}$ Ed.. Routledge; London.

[5] Garvin, D.A. (1998). Managing Quality - The Strategic and Competitive Edge. The free press. New York.

[6] Heizer, J., and Render, B., (2011). Operations Management, tenth edition. Pearson.

[7] Hossain M.M. (2008). Development of Statistical Quality Control: Evolution or Revolution?. Available at: www.decisionsciences.org/Proceedings/DSI2008/docs/196-36 23.pdf [Accessed 4 September 2013]

[8] Juneja, D., Ahmad, S., and Kumar, S., (2011). Adaptability of Total Quality Management to Service Sector. International Journal of Computer Science \& Management Studies, Vol. 11, Issue 02, pp 93-98

[9] Kathuri, J.N., and Pals, D.A. (1993). Introduction to Educational Research. Njoro: Egerton University Press.

[10] Kenya National Bureau of Statistics, (2009). Facts and Figures.

[11] Kothari, C.R., (2004), Research Methodology, second edition. New Age International Publication, New Delhi.

[12] Krejcie and Morgan. (1970). "Determining Sample Size for Research Activities". Educational and Psychological Measurement, No 30, pp. 607-610.

[13] Li, J. and Tsung, F., (2013). Statistical Quality Control for the Service Sector. Available at: www.statistics.gov.hk/wsc/IPS091-P2-S.pdf [Accessed 15 September 2013]

[14] Mahesh, B.P. and Prabhuswamy, M.S., (2010). Process variability reduction through SPC for quality improvement. International Journal for Quality Research, 4(3), pp. 193-203.

[15] Mauch, P.D., (2010). Quality Management: Theory and Application. CRC Press.

[16] Montgomery, D.C., (2009). Introduction to Statistical Quality Control, Sixth Edition. John Wiley \& Sons, Inc.

[17] Moraa, S.O., Etyang, M. and Mwabu G. (2011). The demand for Energy in the Kenyan Manufacturing Sector. The journal of Energy and Development, 34 (2), pp. 265-276.

[18] Mukherjee, A., (2012). Services Sector in India: Trends, Issues and Way Forward. World Economic Outlook.

[19] Mutua, J.W., (2010). The influence of business process re-engineering on customer satisfaction in Kenya Power and Lighting Company Limited. Master's Thesis. University of Nairobi.

[20] Nakhai, B., (2009). The challenges of six sigma in improving service quality. International Journal of Quality \& Reliability Management. Vol. 26 No. 7, pp. 663-684

[21] Njau, E.W., (2011). An investigation of factors affecting performance appraisal in Kenya Power. MBA. Nairobi. Kenyatta University. 
[22] Njoroge, J.K., (2003). Analysis of customer perception of service offered by Kenya power and lighting company ltd in Mount Kenya Region: The Case of Kenya Power and Lighting Company Limited. Master's Thesis. University of Nairobi

[23] Nyaoga, P., (2003). Analysis of customer perception of service offered by Kenya power and lighting company ltd in Mount Kenya Region. Master's Thesis. University of Nairobi.

[24] Oakland, J., (2008). Statistical Process Control, sixth edition. Butterworth-Heinemann

[25] Ograjenšek, I., (2002). Applying Statistical Tools to Improve Quality in the Service Sector. Available at: www.stat-d.si/mz/mz18/ograjen.pdf [Accessed 8 September 2013]

[26] Olatunde, A.A., (2009). On the Importance of Statistical Process Control in Health Care. Research Journal of Medical Sciences, Vol: 3, Issue: 2, pp 87-90.

[27] Ombui, J.M., (2003). Contribution of Information Technology in Business Process Reengineering the case of Kenya Power and Lighting Company. Master's Thesis. Egerton University.

[28] Orumi, N.H., (2009). An assessment of customer perception about service quality at public organizations. (A Case Study of the Kenya Power and Lighting Company LTD). Master's Thesis. University of Nairobi.
[29] Otiso, K.N.; Chelangat, D.; Bonuke, R.N., (2012). Improving the Quality of Customer Service through ICT Use in the Kenya Power and Lighting Company. Journal of Emerging Trends in Economics \& Management Sciences, Vol. 3 Issue 5, pp461.

[30] Owuor, M.O. (2007). Differences in perception of service quality by customers and managers of the Kenya Power and Lighting Company Ltd. Master's Thesis. University of Nairobi

[31] Radhakrishna B. R. (2007). Tips for Developing and Testing Questionnaires/Instruments. Journal of extension. Vol. 45 No. 1, pp. 363-364

[32] Roberts, L., (2005). Applying statistical process control in a Service Environment. Available at: www.r2assoc.com/SPC\%20in\%20a\%20Service\%20Environm ent.pdf [Accessed 7 September 2013]

[33] Scordaki, A., and Psarakis, S. (2005). Statistical process control in service industry an application with real data in a commercial company. In Proc. $7^{\text {th }}$ Hellenic European Conference on Computer Mathematics and Its Applications.

[34] Wood, M., (1994). Statistical Methods for Monitoring Service Processes. International Journal of Service Industry Management, 5(4), pp. 53-68.

[35] M. Young, The Technical Writer's Handbook. Mill Valley, CA: University Science, 198. 